\title{
Hardware in the loop simulation of renewable distributed generation systems
}

\author{
Marco Mauri \\ Department of Mechanics, Politecnico di Milano \\ Italy
}

\section{Introduction}

The strong growth of Distributed Generation (DG) systems installed on Low Voltage (LV) electrical power networks (with a typical power range of 1 to $400 \mathrm{~kW}$ ) has emphasized the need to perform preliminary tests before they are put into service to check their efficiency and validate Power Quality (PQ) functions. Typically, these tests are made on DG system prototypes and entail high experimental cost and effort. In addition, it is often very hard to perform significant tests in a short time because DG systems use renewable energy sources, like the wind or sun that are not always available. A hybrid approach, using Hardware in the Loop (HIL) simulation, has turned out to be an effective tool for the evaluation of these systems and various methods have been proposed in the literature, where Hardware in the Loop (HIL) simulation refers to a system in which parts of a pure simulation have been replaced with actual physical components.

Hardware in the loop simulations (HILS) are not new, but have been used extensively for controller assessment for a long time. The aerospace industry has been using this technique ever since software became a safety critical aspect of flight control systems. More recently, however, a combination of several factors has led to a sharp increase in its use, principally the reduced cost and greater availability of HILS products and the intense pressure to reduce development time and costs.

HIL simulation is now used more and more to develop new components and actuators in many fields. Vehicle component evaluation, drive control assessment, power electronics and electric grids, servo control and robotics, railway traction systems for trains and subways and educational applications can all be cited. More recently, HIL simulations have also been used to test distributed generation systems, e.g., to validate control algorithms or Maximum Power Point Tracking (MPPT) strategies. Generally, these HIL techniques are limited to control applications, i.e., there is only signal coupling between the hardware and the virtual system. This approach, even if it is very useful during the control design stage, presents some deficiencies when it is used to develop electrical drives for renewable low power energy generators.

In these systems, it is very important to evaluate the interactions between the electrical drives and the mechanical components in order to avoid dangerous working conditions and, moreover, to estimate precisely the system's energy efficiency. In particular, this parameter is 
an important variable in a renewable energy plant because these systems are quite expensive and a small increase in global efficiency can drastically reduce the payback time. For this reason, different kinds of HIL simulations can be used to meet these requirements.

\section{HIL simulation concepts for Distributed Generation systems}

DG systems can present different topologies, but a wide number of them require that a static power converter be efficiently connected to an LV network or that active power with a stable voltage and frequency is provided. Indeed, the power converter interface can perform different functions:

- Compensation of reactive power (with or without storage elements).

- Compensation of negative sequence components and components with different frequencies for the current.

- Compensation of voltage sags, micro interruptions and interruptions (with storage elements).

DG sources can rely on both renewable and non-renewable sources, such as wind turbines, photovoltaic generators, small hydro, fuel cells and gas powered combined heat and power (CHP) stations. Figure 1 shows a simplified schematic of a complete DG system.

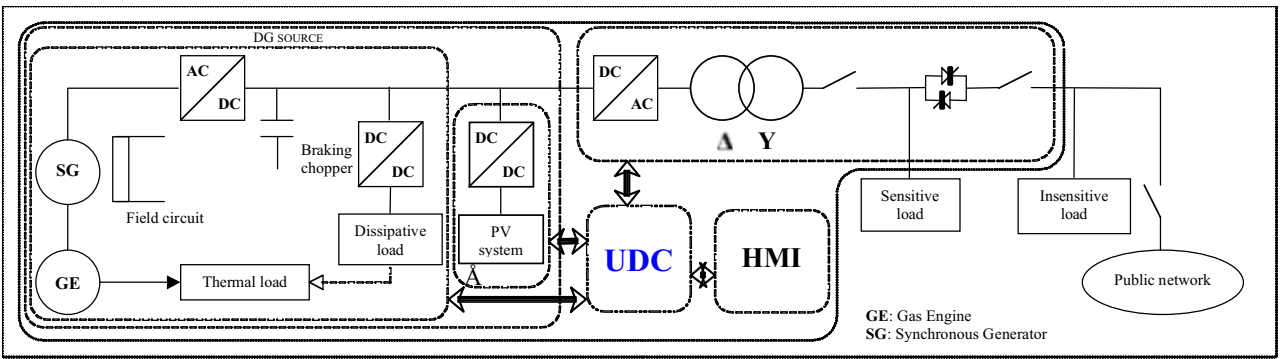

Fig. 1. The simplified architecture of a generic Distributed Generation (DG) system.

The Electrical Drive constitutes the main subsystem of a renewable DG system and the major development effort is often concentrated on this part. An electrical drive can be decomposed into several subsystems: the control software, the power electronics set, the electrical machine and the mechanical load to move (Fig. 2). Typically, a dedicated control board implements the control software and supplies the switching commands to the power electronics converter. Measurements of all the power parts are inputs for the controller board.

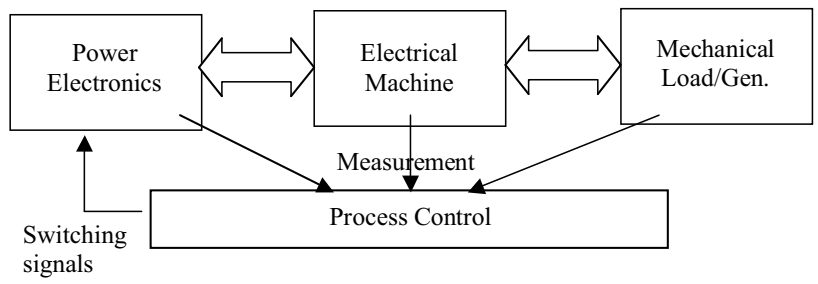

Fig. 2. The Electrical Drive structure. 
In a traditional computer simulation, all of these parts are simulated in the same simulation software environment and, in order to reduce the computation time, simple models and other simplifications are considered (e.g., the sampling period of the control is often neglected). This approach is not always accurate enough to allow a real-time implementation of the control without other intermediate steps. HIL simulation could be a very useful intermediary step: one of the simulated parts can be replaced by its hardware component in order to take into account the real constraints in the simulation loop (Fig. 3).

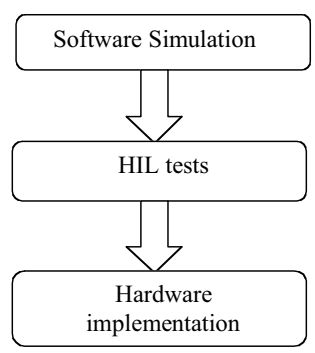

Fig. 3. Electrical Drive design procedure.

Different kinds of HIL simulations can be considered:

- Signal level HIL simulation, where only the control board is tested and the other parts are simulated in real-time. This kind of HIL simulation has very often been employed in aerospace and automotive applications for the assessment of controller boards (Fig. 4).

- Power level HIL simulation, where the control board and the power electronics converter are evaluated and the electrical machine and the mechanical load are simulated (Fig. 5).

- Mechanical level HIL simulation. In this case, the whole drive (control, power electronics and electrical machine) is tested and the mechanical part is simulated (Fig. 6).

Each of these simulations can be used to test a DG electrical drive, although obviously highlighting different aspects and problems.

\subsection{Signal Level HIL simulation}

In a Signal Level Hardware in the Loop Simulation, only the controller board (which contains the process control) is tested (Fig. 4). The other parts (power electronics, machine and mechanical load) are simulated in real-time. The simulation system must manage the inputs and outputs of the controller board under test. A second controller board is thus used to simulate in real-time the power parts of the system. Specific signal conditioning is required to impose the same inputs and outputs as imposed by the power parts. This method can be called "signal level HIL simulation" because only signals are used at the 
interface between the system under test and the simulation environment. This kind of HIL has very often been employed in aerospace and automotive applications for the assessment of controller boards.

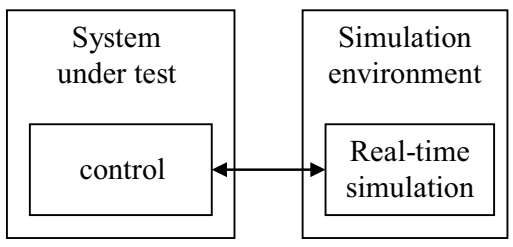

Fig. 4. Signal Level HIL simulation.

\subsection{Power Level HIL simulation}

In a Power Level HIL simulation, the actual controller board and the power electronics converter are evaluated. The other parts (electrical machine and mechanical load) are simulated. The simulation system must impose inputs and outputs for the power electronics and the controller board under test. The simulation environment is generally composed of a second power electronics set (electric load) and a second controller board (real-time simulation) (Fig. 5).

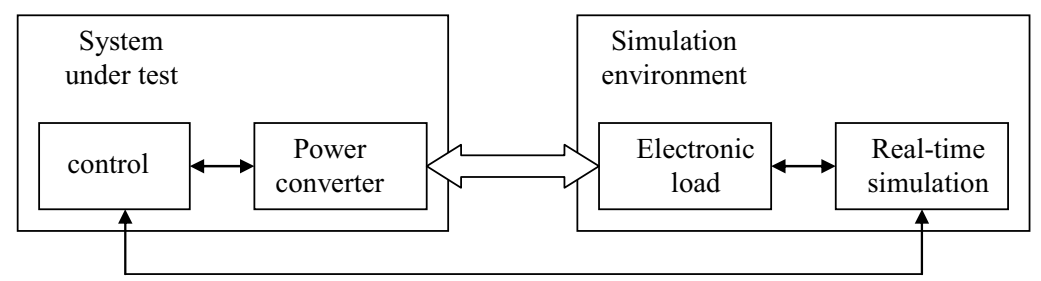

Fig. 5. Power Level HIL simulation.

\subsection{Mechanical Level HIL simulation}

In this case, the whole drive (control, power electronics and electric machine) is tested and the mechanical part is simulated. The simulation system must impose mechanical inputs and outputs on the electrical machine under test. Moreover, measurements on the mechanical part have to be sent to the controller board under test. Another electrical machine (load machine) is often used as a controlled mechanical load. It is supplied by a second power electronics set (load supply). A second controller board (real-time simulation) is required to control the load machine and to send fictitious mechanical "measurements" to the controller board under test (Fig. 6). 


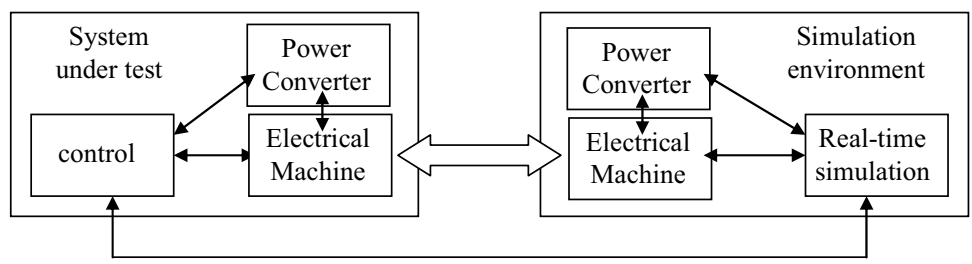

Fig. 6. Mechanical Level HIL simulation.

\section{Real Time modeling concepts}

The implementation of real time models of controlled devices is a well-known problem but becomes a more difficult challenge when the time constraints are very narrow. The simulation models should satisfy different requirements:

- $\quad$ precision and reliability to represent physical system behavior;

- a simple mathematical structure to allow for fast numerical integration and easy software implementation;

- a standard structure for the model equation in order to obtain a more flexible and easily configurable simulation platform.

An Object Oriented approach is typically followed to meet these characteristics during the implementation of emulation models, making it possible to improve the emulator flexibility. Each part of the complete system has been considered as a single object with inputs, outputs and internal states. In this way it is very simple to reconfigure the simulation system without changing the hardware and software structure.

\subsection{Signal Level Modeling}

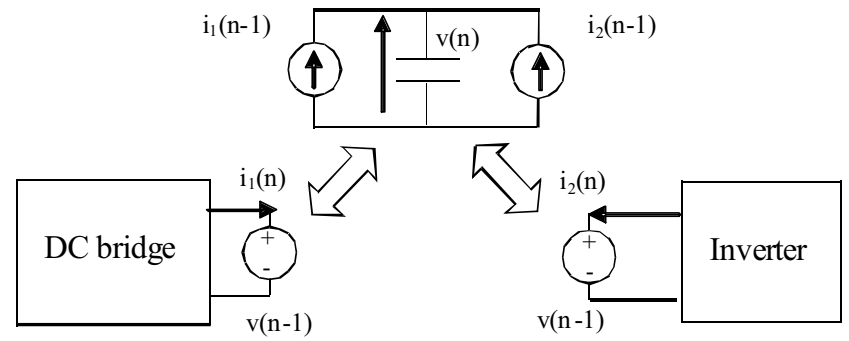

Fig. 7. Example of an Object-Oriented integration procedure for the DC Stage.

In signal level real-time modeling, the smallest bound is the time step necessary to implement the high dynamic behavior of the power electronics stage. This time step is very small (typically 10-100 $\mu \mathrm{s}$ ), so it is necessary to make a great effort to develop suitable models. 
However, a suitable choice for input/output object signals makes it possible to extend the Object Oriented approach during the simulation phase in order to improve the simulation speed because each object can be integrated separately and in a parallel way.

It is obvious that this approximation is acceptable only if input/output object signals change slowly. Signals that satisfy this requirement are the state variables of each subsystem. Figure 7 shows the proposed procedure for the connection between two power converters of a DG system (Fig. 1). The presence of a capacitor on the DC bus makes it possible to decouple the integration of the two power converter models.

Another big problem that is typical of this HIL simulation is the high sampling speed necessary in order to acquire control board switching commands. In order to decouple the acquisition time of the switching state and the integration, the average values of the switching functions are often used instead of the actual values. Different averaging methods are presented in the literature, according to the simulation requirements, especially in the emulation of system faults. An interesting averaging law is presented in (Bucca et al. 2006), where a two level inverter has been modeled using a dedicated acquisition board with two counters. In fact, the output voltage vector of the two-level inverter depends on the DC bus voltage value and on the gate signal sequence only (Fig. 8).

The counter increment is a gate signal function (Table 1) and the mean values of the $\mathrm{d}$ and $\mathrm{q}$ components of the output voltage space vector could be obtained using Equation (1).

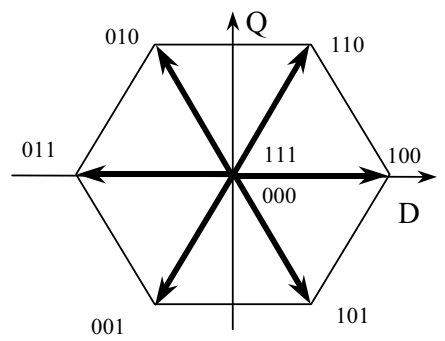

Fig. 8. Output voltage vectors for a two level inverter.

\begin{tabular}{|l|l|l|}
\hline Gate signals & swd & swq increment \\
\hline 000 & 0 & 0 \\
\hline 001 & $-1 / 2$ & $-\sqrt{3} / 2$ \\
\hline 010 & $-1 / 2$ & $\sqrt{3} / 2$ \\
\hline 011 & -1 & 0 \\
\hline 100 & 1 & 0 \\
\hline 101 & $1 / 2$ & $-\sqrt{3} / 2$ \\
\hline 110 & $1 / 2$ & $\sqrt{3} / 2$ \\
\hline 111 & 0 & 0 \\
\hline
\end{tabular}

Table 1. Counter increments. 


$$
\begin{aligned}
& v_{s d}=\sqrt{\frac{2}{3}} V_{D C} \frac{1}{N} \sum_{n=1}^{N} s w_{d}(n) \\
& v_{s q}=\frac{\sqrt{2}}{2} V_{D C} \frac{1}{N} \sum_{n=1}^{N} s w_{q}(n)
\end{aligned}
$$

where:

- $\quad \mathrm{N}$ is the number of gate signal samples during an integration step;

- $\quad \mathrm{sw}_{\mathrm{d}}(\mathrm{n}), \mathrm{sw}_{\mathrm{q}}(\mathrm{n})$ are the $\mathrm{n}$-th values of the counters according to Table 1;

- $\mathrm{V}_{\mathrm{DC}}$ is the value of the DC bus voltage.

Because this voltage is typically used as an input of electrical machine models that are written on a dq axis, this averaging method reduces the number of calculations, with a remarkable improvement in the simulation speed.

\subsection{Power Level Modeling}

Power level HIL simulations have problems similar to Signal level HIL, because the time boundaries depend on the same electrical components.

A big problem in a Power level HIL simulation is that it is necessary to decouple the dynamics of an electronic load from the power electronic converter. Typically, this simulation has been used in DG HIL simulations to test the PV field controller in order to also evaluate the power converter efficiency.

A typical schematic of an HIL power level test bench is shown in Fig. 9.

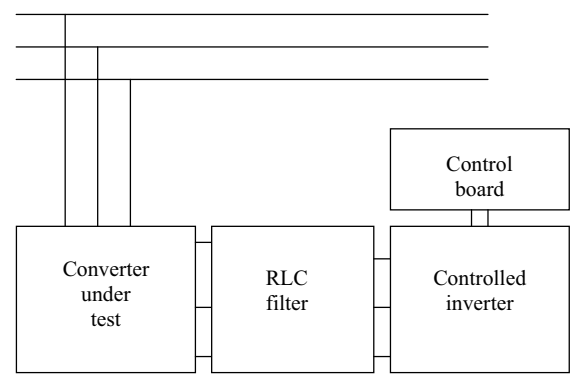

Fig. 9. Schematic of Power level HIL test bench.

A three-phase RLC filter connects the hardware under test with the controlled converter. The filter decouples the operation of the converter from the hardware under test and reduces the ripple introduced by the switching operations of the controlled inverter. In this configuration, the currents drained in each branch of the filter can be regulated by controlling the output voltages of the inverter in order to track the references computed by the real-time simulation. 
A critical step in the realization of this test bench is the measurement of the voltages generated by the converter under test, because these voltages represent the inputs for the real-time simulation. A way to overcome this problem is to estimate these voltages by acquiring the switch signal in a way similar to the signal level HIL test bench, but this structure depends on the control electronics of the converter under test. In fact, the platform interface has to be specifically customized based on the characteristics of the signals that drive the switch gates. In addition, these signals may not be available in industrial converters.

The easiest solution if the gate signals cannot be used is to measure the average voltage of the converter output directly. The voltages are scaled and reduced to a signal level by means of suitable sensors (e.g., hall sensors) that provide galvanic isolation, and then they are averaged over a simulation period. The main advantage of this technique is that the voltage used in the real-time simulation is reconstructed from the power signal instead of the gate signal in order to include switching non-linearity and improve the HIL test bench standardization.

\subsection{Mechanical Level Modeling}

In a mechanical level HIL simulation, the presence of a real electrical drive removes the very small time step boundaries of signal level and power level HIL simulations and introduces new boundaries that depend on mechanical dynamics (2).

$$
T_{m}=T_{r}+J \frac{d \omega}{d t}
$$

where $T_{m}$ is the electromagnetic torque, $T_{r}$ is the load torque and $J$ is the equivalent inertia. Equation (2) shows that the electrical drive used to emulate the mechanical load should supply not only the load torque but also the inertial torque, which could present high values and dynamics. To satisfy this requirement, it is necessary to use a high performance drive, which is not very simple to implement and control.

To avoid this problem, a different approach can be used, as proposed in (). In particular, the DG power source presents a low dynamic speed variation due to a high damping factor and inertia, so it is possible to modify the mechanical emulator control of the electrical drive from torque to speed control. In this way, the mechanical model could be reduced to a quasi-steady-state model by considering the DG power source speed as a constant during the integration step. This is possible because the integration model step is very small compared with the mechanical time constants, due to the previous considerations.

Using this approach, the acceleration torque can be calculated by subtracting the load power $\left(\mathrm{P}_{1}\right)$ from the available mechanical source power $\left(\mathrm{P}_{\mathrm{s}}\right)$ and dividing the result by the actual speed. The load power is measured by the electrical drive to take into account all the mechanical losses in the power train.

The new speed reference $\left(\omega_{\mathrm{ref}}\right)$ for the electrical drive that emulates the DG power source is calculated by dividing the acceleration torque by the system equivalent inertia, as is indicated in (3) and (4) and represented in Fig. 10. 


$$
\begin{gathered}
T_{a}=\frac{P_{s}-P_{l}}{\omega_{a c t}} \\
\frac{d\left(\Delta \omega_{m}\right)}{d t}=\frac{1}{J} T_{a c c}-B \omega_{a c t} \\
\Delta \omega_{m}=\int_{0}^{\Delta t}\left(\frac{T_{a}}{J}+B \omega_{a c t}\right) d t \Rightarrow \omega_{r e f}=\omega_{a c t}+\Delta \omega_{m}
\end{gathered}
$$

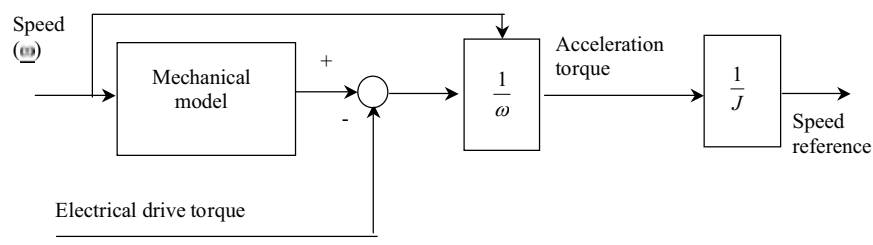

Fig. 10. Calculation of the new speed reference.

The proposed approach simplifies the modeling of high inertia loads, making it possible to test control strategies under dynamic conditions, while avoiding the measurement of load acceleration. Moreover, it is possible to use a less sophisticated electrical drive, control board and emulation board, thus reducing the test bench cost.

A different approach was proposed in (Kuperman and Rabinovici, 2005), where the simulation of load variation was introduced by adding a virtual load signal to the output of the electrical motor controller. Even though this approach is very interesting, it is very difficult to implement it, because it is necessary to modify the controller software.

\section{Experimental results}

In the following sections, some experimental results using different HIL configurations are presented.

\begin{tabular}{|c|c|}
\hline Motor & \\
\hline Rated power at $50 \mathrm{~Hz}$ & $370 \mathrm{~W}$ \\
\hline Rated torque & $1.3 \mathrm{Nm}$ \\
\hline Rated speed & $2820 \mathrm{rpm}$ \\
\hline Rated current & $1.7 \mathrm{~A}$ \\
\hline Starting current & $4.56 \mathrm{~A}$ \\
\hline Power factor & 0.83 \\
\hline Starting Torque & $3.9 \mathrm{Nm}$ \\
\hline Rotor inertia & $3.5 \times 10^{-4} \mathrm{kgm}^{2}$ \\
\hline Nr. of pole pairs & 1 \\
\hline Statoric phase resistance & $24.6 \Omega$ \\
\hline Rotoric phase resistance & $16.1 \Omega$ \\
\hline Magnetizing inductance & $1.46 \mathrm{H}$ \\
\hline Electrical Time constant & $1.62 \times 10^{-3} \mathrm{~s}$ \\
\hline
\end{tabular}




\begin{tabular}{|c|c|}
\hline Converter & \\
\hline Input voltage & single-phase $180-240 \mathrm{~V}$ \\
\hline Output power & $750 \mathrm{~W}, 150 \%$ overl.1 min. \\
\hline Output voltage & $0-230 \mathrm{~V}$ \\
\hline Power switches & IGBT \\
\hline
\end{tabular}

Table 2. Emulated Converter and Motor characteristics.

\subsection{Signal Level HIL simulation}

An example of a real-time emulator hardware structure for signal level HIL simulations is presented in Fig. 11. The HIL test bench emulates an asynchronous drive with the characteristics indicated in Table 2. The electrical drive used for the test was a Technosoft induction motor drive with a control board based on TMS320F240 DSP.

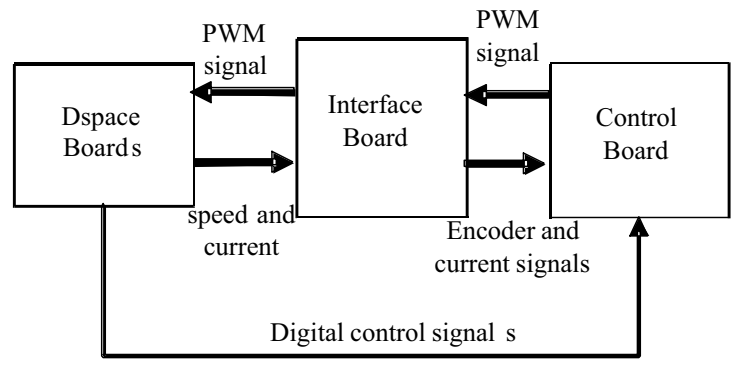

Fig. 11. Signal level HIL test bench architecture.

A dSpace system (ds1006 board based) was used to integrate the electrical drive models, acquire the PWM signal and generate speed and current signals. A dedicated interface board was used to adapt the analogue signal levels and generate the encoder signals.

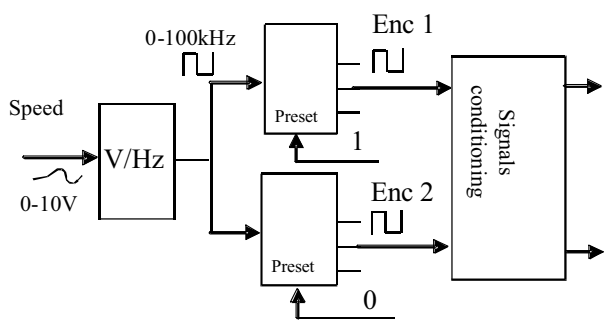

Fig. 12. Encoder emulation.

The encoder signal generation was done using a Voltage/Frequency converter and two digital counters (Fig. 12). The basic idea was based on the observation that if the counter 
chips have been initialized to 0 and 1, respectively, the output 2 nd bit signals are square signals with a $\Pi / 2$ phase shift.

Fig. 13 shows the phase current and speed signals acquired by the control board for different speed transients. The induction motor was controlled using close loop field oriented control.

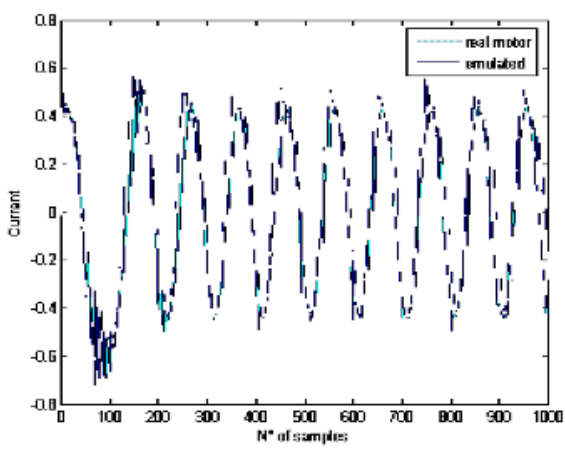

a) Phase current

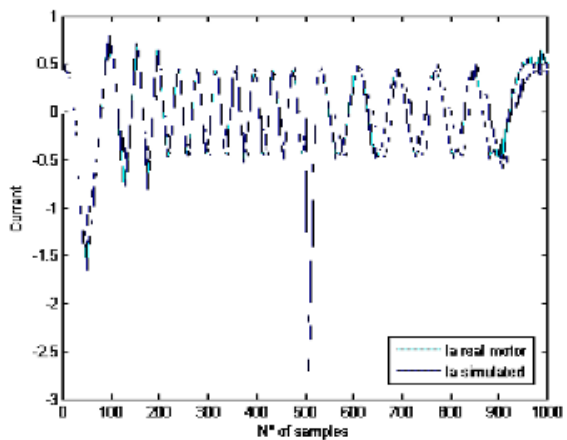

c) Phase current

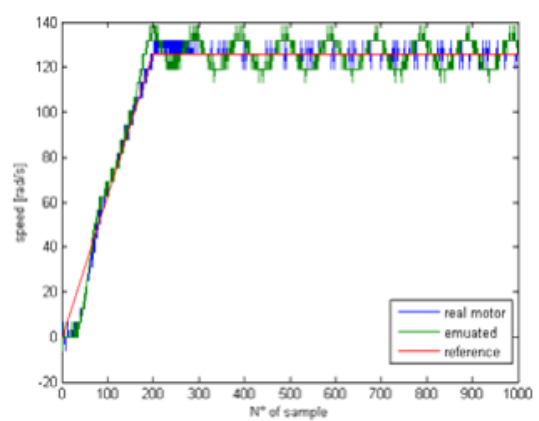

b) Speed

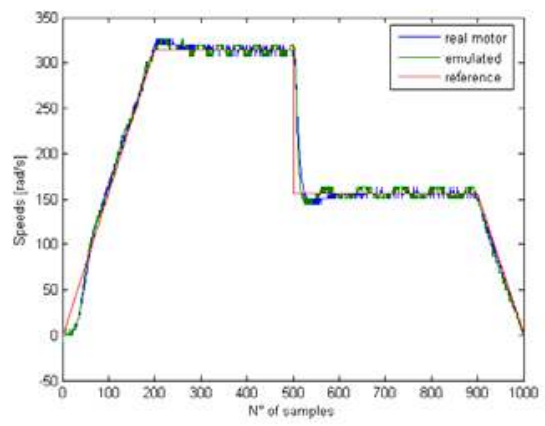

d) Speed

Fig. 13. Comparison between real motor acquisition and emulated system acquisition of phase current and speed for different speed transients.

It is interesting to note that the real transients and emulated transients are very similar. There was a little difference in the first speed acquisition (Fig. 13b), but it was practically limited to the less significant bit of the digital acquisition. This difference was principally caused by the absence of any additional conditioning stage between the encoder emulation board and the control board and was more significant at low speed (comparing Fig. 13b-d).

\subsection{Power Level HIL simulation}

A power level HIL simulation of a PV field was performed. A typical configuration for a photovoltaic (PV) generator is shown in Fig. 14. 


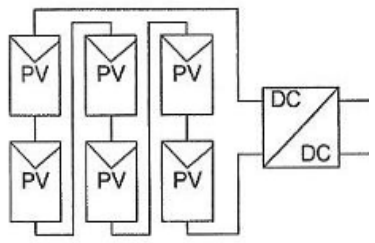

Fig. 14. Configuration of emulated PV field.

Normally a set of PV modules is series and parallel connected to form a PV multiple module or PV subfield, with suitable rated voltage and current. The PV subfield is then connected to a DC-DC converter. It is also possible to connect individual PV strings to their own DC-DC converters. The PV generator can work either in a grid connection mode or in stand alone operation without a storage system, thanks to a suitable control strategy. When a photovoltaic system works in the grid connection mode, a MPPT control technique is implemented in order to extract the maximum electrical energy from the PV panel.

Using the HIL test bench, a DC/DC converter for a PV field with a Perturb and Observe MPPT algorithm was tested. The behavior of a SHELL SQ8 PV panel was emulated. Fig. 15 shows the behavior of a SHELL SQ8 PV panel for different irradiance levels and temperatures.
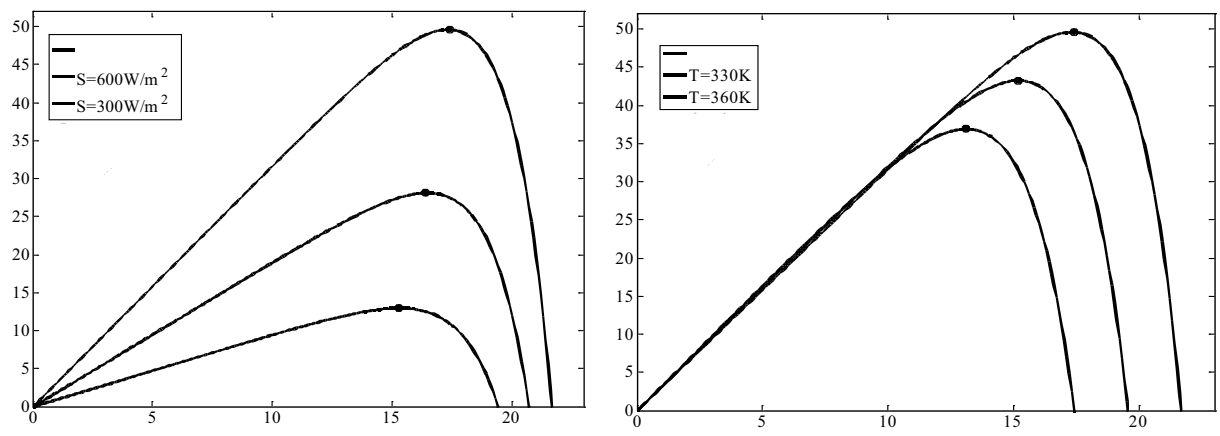

Fig. 15. SHELL Q8 PV V/I characteristics.

The implemented $\mathrm{P} \& \mathrm{O}$ algorithm operates by periodically perturbing (i.e., incrementing or decrementing) the array terminal voltage and comparing the PV output power with that of the previous perturbation cycle. If the PV array operating voltage changes and the power increases $\left(\mathrm{dP} / \mathrm{dV} V_{\mathrm{PV}}>0\right)$, the control system moves the PV array operating point in that direction; otherwise the operating point is moved in the opposite direction. In the next perturbation cycle, the algorithm continues in the same way.

A common problem in $\mathrm{P} \& \mathrm{O}$ algorithms is that the array terminal voltage is perturbed every MPPT cycle; therefore when the MPP is reached, the output power oscillates around the maximum, resulting in power loss in the PV system. This is especially true in constant or slowly-varying atmospheric conditions, but also occurs under rapidly changing atmospheric conditions (in this case the perturbation direction can be wrong). 
There are many different $\mathrm{P} \& \mathrm{O}$ methods available in the scientific literature. In this case, a modified $\mathrm{P} \& \mathrm{O}$ algorithm was adopted in which the perturbation amplitude of the PV operating point has a constantly variable magnitude. The magnitude of the perturbation is a function of the power variation necessary to reach the target.

a)

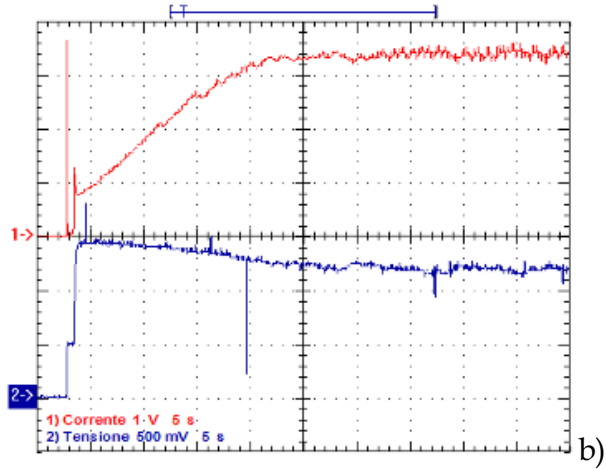

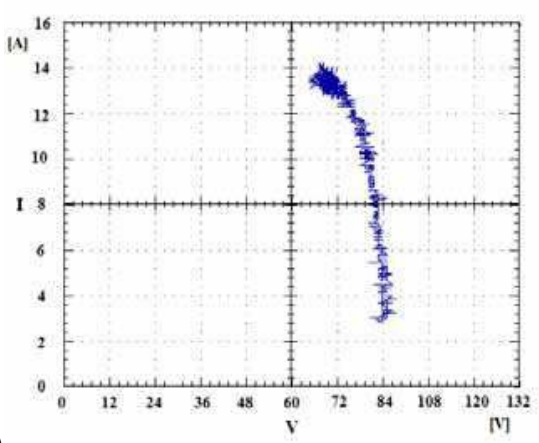

Fig. 16. a) $1 \mathrm{~kW}$ PV subfield I/V output characteristics during start up phase $(\mathrm{I}=20 \mathrm{~A}=>5 \mathrm{~V}$; $\mathrm{V}=300 \mathrm{~V}=>5 \mathrm{~V}$ ) b) I/ $\mathrm{V}$ characteristics during start up phase of MPPT control.

a)

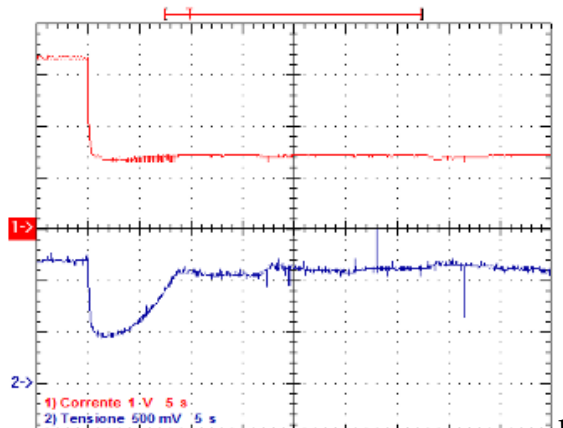

b)

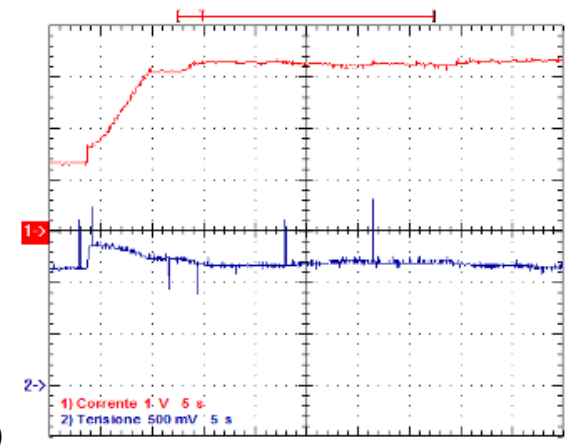

Fig. 17. $1 \mathrm{~kW}$ PV subfield I/V output characteristics when variable step $\mathrm{P} \& \mathrm{O}$ algorithm is used $(\mathrm{I}=20 \mathrm{~A}=>5 \mathrm{~V} ; \mathrm{V}=300 \mathrm{~V}=>5 \mathrm{~V}$ ), a) during power discharging (from $1000 \mathrm{~W}$ to $400 \mathrm{~W}$ ) and b) during power changing (from $400 \mathrm{~W}$ to $1000 \mathrm{~W}$ ).

Fig. 16 presents the V/I characteristics during the PV subfield start up simulation. The PV subfield current starts from a null value with the maximum voltage value and reaches the MPP in 30 seconds, with constant current ripple amplitude.

An instantaneous reduction in the PV subfield power from $1000 \mathrm{~W}$ to $400 \mathrm{~W}$ was simulated. The MPP changes from $74 \mathrm{~V}-13 \mathrm{~A}$ to $69 \mathrm{~V}-5,5 \mathrm{~A}$. Fig. 17 represents the algorithm behavior during an instantaneous increase from $400 \mathrm{~W}$ to $1000 \mathrm{~W}$. The MPP changes from 69V-5,5A to 74V-13A. 


\subsection{Mechanical Level HIL simulation}

Two different DG systems were emulated using an HIL mechanical level test bench.

- $\quad$ small CHP Generating Set

- Small-scale hydropower generator

\subsubsection{Small CHP generating set.}

Small power CHP (Combined Heat and Power) generating sets, based on internal combustion engines, are normally grid-connected and have a power range of $10 \mathrm{~kW}$ to 100 $\mathrm{kW}$. These small CHP generating sets can be equipped with both diesel engines and gas fuelled engines. The advantage of using combined heat and power generation is that the global efficiency can be increased to 85 to $90 \%$, which make them a very favorable solution for Distributed Generation systems. The most convenient arrangement is to use an asynchronous generator, even if it shows some drawbacks. In particular, it requires reactive power for the excitation of its magnetic circuits and, in the case of failure of the mains, it does not work in a stand alone mode to provide electrical power to the on-site ac load.

Conventional CHP sets work at a fixed speed in order to generate electrical power at a fixed frequency, but they show low energy efficiency when they operate at partial load. An improvement can be obtained by using a variable speed gas engine to drive the electrical generator at a variable frequency. Operating the CHP set at a variable speed makes it possible to achieve the highest energy conversion efficiency at any partial load of more than $20 \%$, but it is necessary to use an $\mathrm{AC} / \mathrm{AC}$ frequency converter in order to connect the variable speed $\mathrm{CHP}$ set to the public grid.

The behavior of a variable speed CHP set can be further enhanced by introducing an additional DC/DC static converter, in order to increase the amount of electrical power that can be transformed into heat (dissipating electrical power on a resistor). In this way, a control strategy with heating priority can meet a temporary high demand for heat, reducing the production of electricity.

\subsubsection{Small-scale hydropower generator}

Hydroelectric generation has been well recognized as environmentally friendly and socially beneficial for many applications, but large-scale hydroelectric plant developments have become more and more difficult because of the shortage of undeveloped suitable sites and concerns about global environmental protection. However, there are many sites where it is possible to install a small-scale hydroelectric plant.

These systems normally adopt expensive Kaplan turbines that allow optimal control of the water flow. In order to reduce plant costs in small-scale plants, it is preferable to use fixedblade propeller water turbines.

This choice can reduce the plant power efficiency because typically in traditional hydroelectric power plants, the speed of the generating unit remains constant to keep it synchronized with the grid, neglecting turbine discharge variation over time. Moreover, this situation becomes critical in stand-alone operation mode, where keeping the speed of the generation unit constant reduces the power plant efficiency drastically. In these cases, a variable speed operation mode and maximum power efficiency operation point tracking is welcome, but it presents numerous design problems regarding the definition of the 
hardware architecture and power management strategies. Such small-scale hydroelectric plants generally use a PM synchronous machine as an electrical generator.

\subsubsection{The HIL test bench}

Each of these applications presents similar problems. In particular, it is very important to evaluate the mechanical performance and, moreover, it is necessary to evaluate the global efficiency (converter and motor) with a good approximation. This it is very difficult to do using an HIL environment where the power converter is also emulated: the calculation effort necessary to simulate the electrical drive characteristics and losses does not allow simple and low cost real-time implementation.

Because of these considerations, mechanical emulation is the better choice. An example of mechanical test bench hardware architecture is shown in Fig. 18, which includes:

- A motor drive, including an inverter controlled squirrel cage induction motor. This motor was used to emulate the static and dynamic mechanical behavior of the DG power source. An incremental optical encoder was used to feed back the speed signal for control and emulation purposes.

- A DC motor was used to emulate the generator side of the DG system. The rated parameters of the induction motor and generator are listed in Table I.

\begin{tabular}{|l|l|l|l|}
\hline \multicolumn{2}{|c|}{ Induction Motor } & \multicolumn{2}{c|}{ DC Motor } \\
\hline Rated voltage & $380 \mathrm{~V}$ & Rated voltage & $240 \mathrm{~V}$ \\
\hline Rated current & $35.1 \mathrm{~A}$ & Rated current & $60 \mathrm{~A}$ \\
\hline Rated Power & $18.5 \mathrm{~kW}$ & Rated power & $14 \mathrm{~kW}$ \\
\hline Power factor & 0.88 & & \\
\hline Rated speed & $1465 \mathrm{rpm}$ & Rated speed & $1500 \mathrm{rpm}$ \\
\hline $\begin{array}{l}\text { Wound } \\
\text { connection }\end{array}$ & $\mathrm{D}$ & & \\
\hline $\mathrm{N}^{\circ}$ of poles & 4 & $\mathrm{~N}^{\circ}$ of poles & 4 \\
\hline
\end{tabular}

Table 3. Induction Motor and DC Motor rated Parameters. 


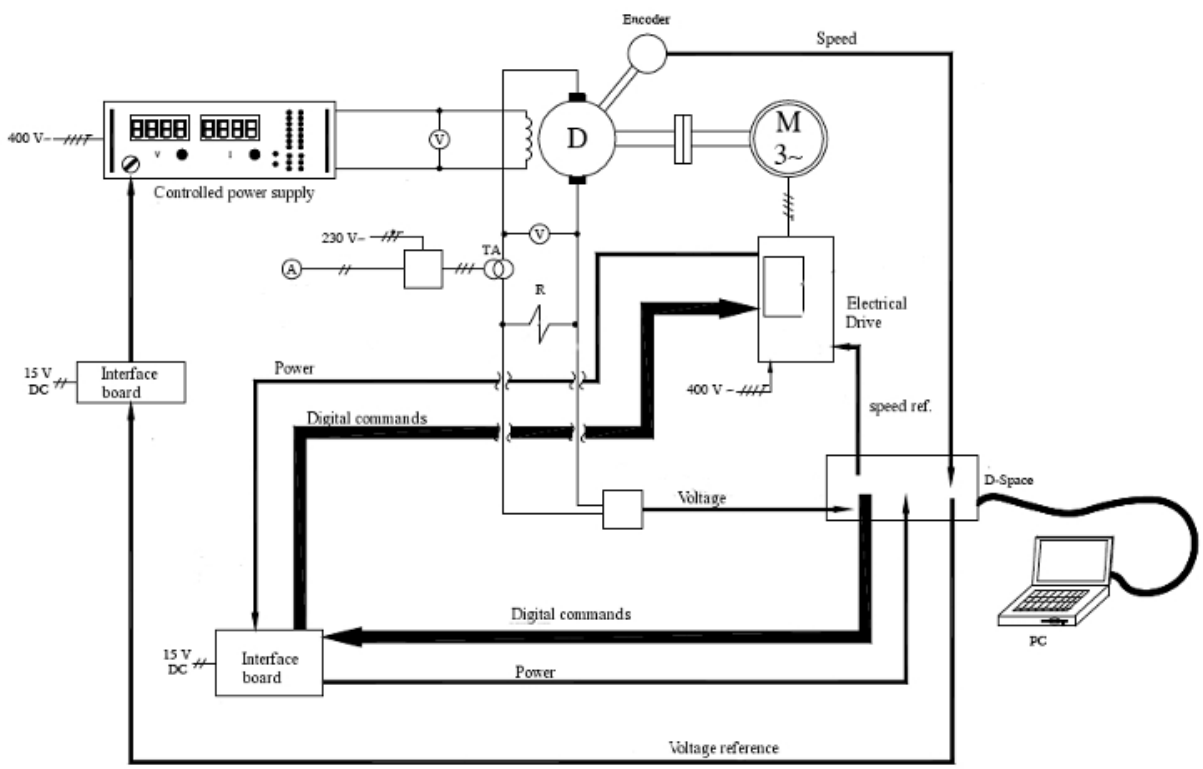

Fig. 18. Example of mechanical HIL test bench

- A desktop PC with a dSpace 1104 board that implements the DG power source model. A dedicated interface board was used to acquire measurement signals from the field and the motor drive and to transmit control reference signals from the dSpace board to the motor drive.

- $\quad$ A passive load to dissipate the generated power.

\subsubsection{Experimental results}

According to the previous discussion, when simulating the gas engine of a CHP system, it is necessary to evaluate the equivalent inertia and damping factor, along with the generated power vs. rotational speed curve. In a gas engine, this curve is proportional to the throttle valve opening. 


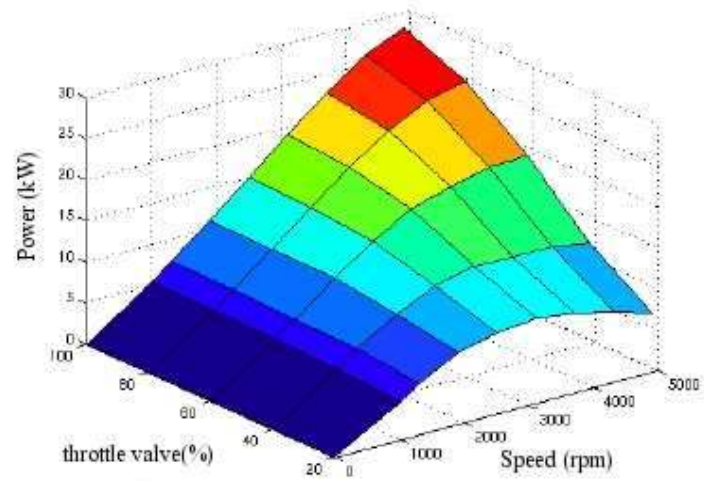

Fig. 19. Generated power vs. speed and throttle valve opening.

Fig. 19 represents the generated power vs. rotational speed for different throttle valve openings (in percentage) for a $30 \mathrm{~kW}$ gas engine. In order to validate different control strategies, it was also necessary to emulate the fuel consumption under different load conditions. Fig. 20 shows the fuel flow in $\mathrm{kg} / \mathrm{h}$ vs. speed and the throttle valve openings for the same motor.

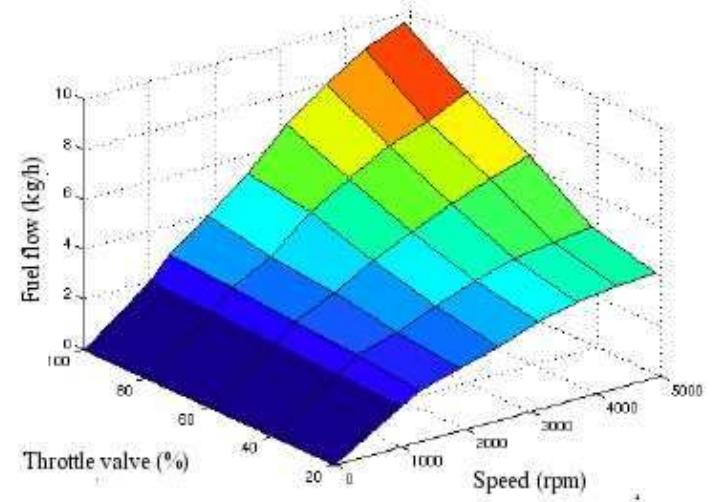

Fig. 20. Fuel flow vs. speed and throttle valve opening.

$$
\begin{aligned}
& J=4 \mathrm{~kg} / \mathrm{m}^{2} \\
& B=3 J /(\mathrm{rad} / \mathrm{s})
\end{aligned}
$$

The estimated inertia and damping factor of the motor are indicated in (6).

The fixed blade turbine of a small-scale hydropower plant can be modeled in the same way as the gas engine. In this case, the turbine discharge $(Q)$ and efficiency $(\eta)$ vs. speed are obtained using the steady-state curves and these values are used in combination with the turbine head $(\mathrm{H})$ to calculate the available mechanical power (6). Table 4 shows the parameters used. 


$$
P_{h y d}=H Q g \cdot \eta
$$

\begin{tabular}{|l|l|}
\hline Rated power & $3.2 \mathrm{~kW}$ \\
\hline Rated discharge & $0.1 \mathrm{~m}^{3} / \mathrm{s}$ \\
\hline Design head & $5.2 \mathrm{~m}$ \\
\hline Rated Rotational Speed & $180 \mathrm{rpm}$ \\
\hline
\end{tabular}

Table 4. Hydro turbine technical data.

$$
\begin{aligned}
& J=10 \mathrm{~kg} / \mathrm{m}^{2} \\
& B=50 \mathrm{~J} /(\mathrm{rad} / \mathrm{s})
\end{aligned}
$$

The efficiency of the system depends on the opening of the distributing valve and the speed as indicated in Fig. 21, and the turbine speed is considered to have a constant value during the integration step (in this case it was set to $100 \mathrm{~ms}$ ).

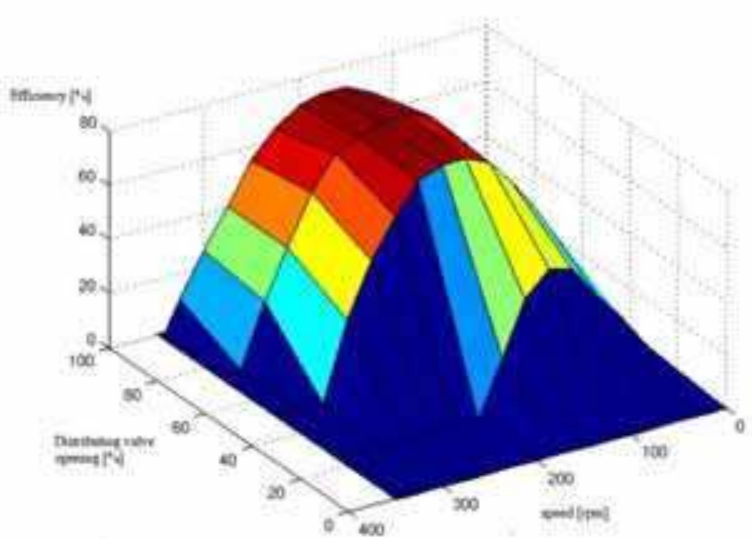

Fig. 21. Efficiency vs. turbine speed and distributing valve opening.

Fig. 22 shows the generated power reference vs. time and the real generated power vs. time using the hydropower turbine model, emulating a grid connection working mode. Fig. 13 compares the estimated generated power using the HIL hydropower model and the real power dissipated on the resistive load of the test bench. The power reference was calculated based on the load variations, while the generated power should also take into account the plant losses. These losses produced the stationary difference between the generated power and power reference. 


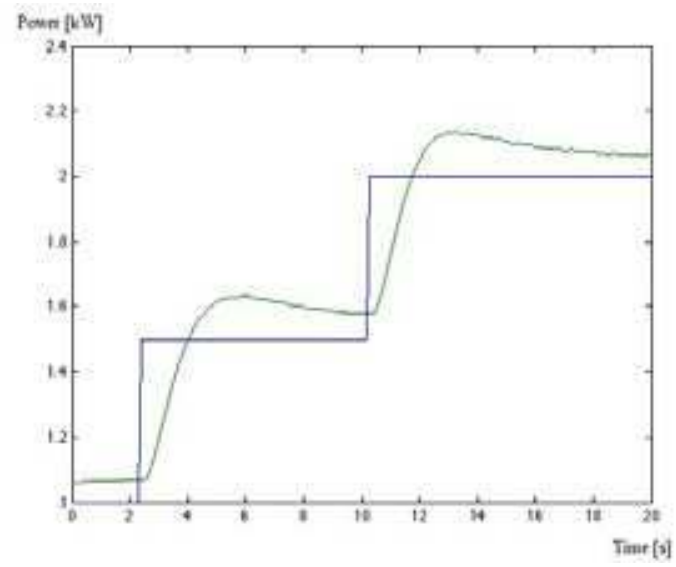

Fig. 22. Power reference and generated power vs. time.

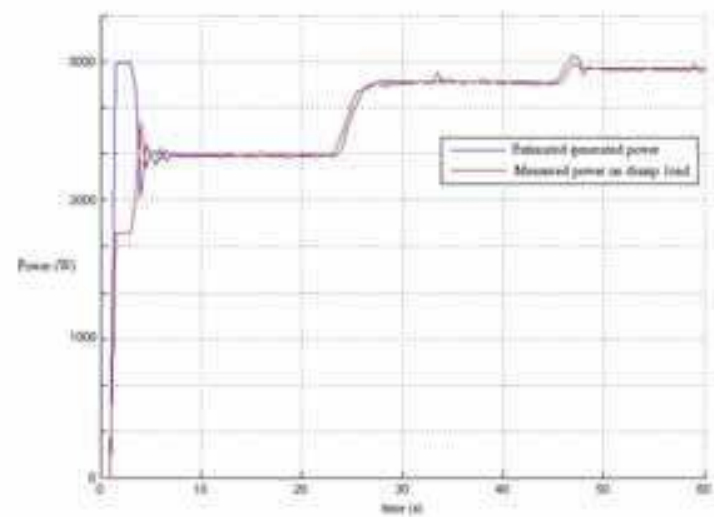

Fig. 23. Estimated generated power (from HIL test bench) and dissipated power on the resistive load.

\section{Conclusion}

Hardware in the loop simulations (HILS) are a powerful method to test DG system components, such as control system electronics, without connection to the real equipment under control.

The use of this technique does, however, raise challenges, such as complex interfacing requirements and the execution of an accurate equipment simulation that must operate in real-time.

The increasing adoption of HILS has been driven by a number of factors, including the ability to perform system testing before the complete system is available and to simulate failure conditions that would be dangerous or expensive to create in a real plant. 
HILS is an important tool to reduce development time and ensure the safety and reliability of DG components. The availability of cost effective tools to perform HILS should lead to an increase in the use of this technique as a standard method to test DG components.

\section{References}

Bouscayrol (2008). Different types of Hardware-In-the-Loop simulation for electric drives. Proceedings of IEEE International Symposium on Industrial Electronics, 2008. ISIE 2008. pp. 2146 - 2151, ISBN 978-1-4244-1665-3, Cambridge, July 2008, IEEE

Bin Lu; Xin Wu; Figueroa, H. \& Monti, A. (2007). A Low-Cost Real-Time Hardware-in-theLoop Testing Approach of Power Electronics Controls. Industrial Electronics, IEEE Transactions on, vol. 54 n. 2, pp. 919 - 931, ISSN 0278-0046

Bucca G.; Mapelli F. \& Mauri M. (2006). A Real-time environment for industrial electrical drive control board testing. Proceedings of International Conference on Electrical Machines, ICEM2006

Facchinetti A. \& Mauri M. (2008). Hardware in the loop test-rig for pantograph active control evaluation. Proceedings of IEEE International Symposium on Industrial Electronics, 2008. ISIE 2008, pp. 2171 - 2176, ISBN 978-1-4244-1665-3, Cambridge, July 2008, IEEE

Jian Wu; Yong Cheng; Srivastava A.K.; Schulz N.N.; Ginn, H.L.. (2006). Hardware in the Loop Test for Power System Modeling and Simulation. Proceedings of Power Systems Conference and Exposition, 2006. PSCE '06, pp. 1892-1897, ISBN 1-4244-0177-1, Atlanta GA, November 2006, IEEE PES

Kuperman A. \& Rabinovici R. (2005) Virtual torque and inertia loading of controlled electric drive. Education, IEEE Transactions on, vol. 48 n.1, pp. 47- 52, ISSN 0018-9359.

Maclay D. (1997). Simulation gets into the loop. IEE Review vol. 43 n. 3, pp. 109 - 112, ISSN 0953-5683

Mohan, N.; Robbins, W.P.; Undeland, T.M.; Nilssen, R. \& Mo, O. (1994) Simulation of power electronic and motion control systems-an overview. Proceedings of the IEEE, vol. 82 n. 8, pp. 1287 - 1302, ISSN 0018-9219

Mauri M; Castelli Dezza F. \& G. Marchegiani (2007). A novel small-scale variable speed hydropower emulator using an inverter-controlled induction motor. Proceedings of European Conference on Power Electronics and Applications, 2007 pp. 1-7, ISBN: 978-9275815-10-8, Aalborg, September 2007, IEEE

Mauri M.; Castelli Dezza F. \& Marchegiani G. (2008). Hardware in the Loop (HIL) test bench for small-scale Distributed Generation systems. Proceedings of IEEE International Symposium on Industrial Electronics, 2008. ISIE 2008, pp. 2177 - 2182, ISBN 978-14244-1665-3, Cambridge, July 2008, IEEE

Shi Y. \& Monti A. (2008). FPGA-based fast real time simulation of power systems. Proceedings of Power and Energy Society General Meeting - Conversion and Delivery of Electrical Energy in the 21st Century, pp. 1 - 5, ISBN 978-1-4244-1905-0, July 2008, IEEE 


\section{Renewable Energy}

Edited by $\mathrm{T} \mathrm{J}$ Hammons

ISBN 978-953-7619-52-7

Hard cover, 580 pages

Publisher InTech

Published online 01, December, 2009

Published in print edition December, 2009

Renewable Energy is energy generated from natural resources-such as sunlight, wind, rain, tides and geothermal heat-which are naturally replenished. In 2008 , about $18 \%$ of global final energy consumption came from renewables, with $13 \%$ coming from traditional biomass, such as wood burning. Hydroelectricity was the next largest renewable source, providing $3 \%$ (15\% of global electricity generation), followed by solar hot water/heating, which contributed with 1.3\%. Modern technologies, such as geothermal energy, wind power, solar power, and ocean energy together provided some $0.8 \%$ of final energy consumption. The book provides a forum for dissemination and exchange of up-to-date scientific information on theoretical, generic and applied areas of knowledge. The topics deal with new devices and circuits for energy systems, photovoltaic and solar thermal, wind energy systems, tidal and wave energy, fuel cell systems, bio energy and geo-energy, sustainable energy resources and systems, energy storage systems, energy market management and economics, off-grid isolated energy systems, energy in transportation systems, energy resources for portable electronics, intelligent energy power transmission, distribution and inter-connectors, energy efficient utilization, environmental issues, energy harvesting, nanotechnology in energy, policy issues on renewable energy, building design, power electronics in energy conversion, new materials for energy resources, and RF and magnetic field energy devices.

\section{How to reference}

In order to correctly reference this scholarly work, feel free to copy and paste the following:

Marco Mauri (2009). Hardware in the Loop Simulation of Renewable Distributed Generation Systems, Renewable Energy, T J Hammons (Ed.), ISBN: 978-953-7619-52-7, InTech, Available from: http://www.intechopen.com/books/renewable-energy/hardware-in-the-loop-simulation-of-renewabledistributed-generation-systems

\section{INTECH}

open science | open minds

\section{InTech Europe}

University Campus STeP Ri

Slavka Krautzeka 83/A

51000 Rijeka, Croatia

Phone: +385 (51) 770447

Fax: +385 (51) 686166

www.intechopen.com

\section{InTech China}

Unit 405, Office Block, Hotel Equatorial Shanghai

No.65, Yan An Road (West), Shanghai, 200040, China 中国上海市延安西路65号上海国际贵都大饭店办公楼405单元

Phone: +86-21-62489820

Fax: +86-21-62489821 
(C) 2009 The Author(s). Licensee IntechOpen. This chapter is distributed under the terms of the Creative Commons Attribution-NonCommercial-ShareAlike-3.0 License, which permits use, distribution and reproduction for non-commercial purposes, provided the original is properly cited and derivative works building on this content are distributed under the same license. 